\title{
NÚMEROS COMPLEXOS: FORMA POLAR E EXTRAÇÃO DE RAÍZES
}

\section{Pamela Rafaela de Oliveira ${ }^{1}$ Orientador: Lucas Antonio Caritá ${ }^{2}$}

Resumo: Este trabalho tem como objetivo apresentar e justificar as propriedades válidas para os números complexos em sua representação polar (ou trigonométrica) e tratar o problema de extração de raízes de um número complexo. Para isso, o foco teórico foi definir um número complexo em sua representação polar com base na sua representação algébrica, apresentar e justificar suas propriedades válidas e em sequência, a partir de um teorema, definir as raíz n-ésimas de um número complexo. As propriedades e demonstrações foram apresentadas e justificadas de forma clara e matematicamente coerentes.

Palavras-chave: Números complexos; Forma polar; Raízes complexas.

\footnotetext{
1 Instituto Federal de Educação, Ciência e Tecnologia de São Paulo, Brasil. E-mail: pam99130178@gmail.com. 2 Instituto Federal de Educação, Ciência e Tecnologia de São Paulo, Brasil. Email: prof.carita@ifsp.edu.br.
} 